\title{
Cyclodextrin-induced host-guest effects of classically prepared poly(NIPAM) bearing azo-dye end groups
}

\author{
Gero Maatz, Arkadius Maciollek and Helmut Ritter ${ }^{*}$
}

\section{Full Research Paper}

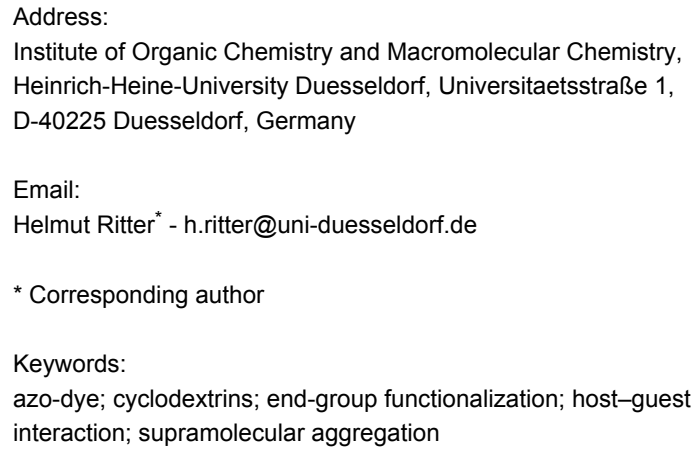

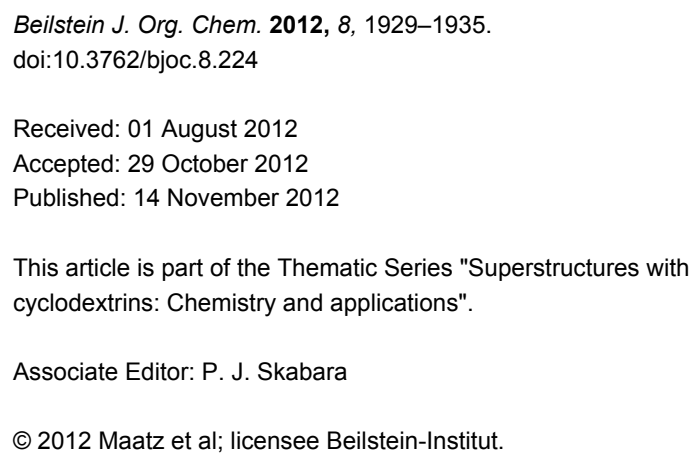

\begin{abstract}
A thermo-, $\mathrm{pH}$ - and cyclodextrin- (CD) responsive poly( $N$-isopropylacrylamide) (PNIPAM), with a $N, N$-dimethylaminoazobenzene end group was synthesized. Using 3-mercaptopropionic acid as a chain transfer agent, PNIPAM with a well-defined $\mathrm{COOH}$ end group was obtained. The acid end group was transferred to the corresponding acid chloride and then functionalized with $N, N$ dimethyl[4-(4'-aminophenylazo)phenyl]amine. This dye-end-group-labeled polymer showed acidochromic effects, depending on the $\mathrm{pH}$ and the presence of randomly methylated $\beta$-cyclodextrin (RAMEB-CD). Also higher cloud-point values for the lower critical solution temperature (LCST) in the presence of RAMEB-CD were observed. Additionally, this azo-dye-end-group-labeled polymer was complexed with hyperbranched polyglycerol (HPG) decorated with $\beta$-CD to generate hedgehog-like superstructures.
\end{abstract}

\section{Introduction}

Polymers bearing dyes, such as azo, stilbene, anthraquinone or fluorescence dyes, in the main or side chain have been widely described and investigated [1-15]. A few examples of dyes located at the end group of polymers are prepared preferably under anionic or controlled conditions such as reversible addition-fragmentation chain-transfer polymerization (RAFT) or atom-transfer radical polymerization (ATRP) [14-16]. However, up to now, only a little is known about the prepar- ation of dye-end-group-labeled polymers by using classical free-radical polymerization techniques. Water-soluble polymers, which exhibit a lower critical solution temperature (LCST), e.g., many poly( $N$-alkylacrylamides), have found numerous practical applications in waterborne smart materials such as bioactive surfaces, selective bioseparation, or hyperthermia-induced drug delivery [14]. Several reports are available on the preparation and properties of thermally responsive 
polyacrylamides containing azobenzene or stilbene dyes in the side chain $[3,14]$. Furthermore, the interaction of dye-containing polymers with $\mathrm{CD}$ in water is of some interest, because of their external, light-induced, reversible complexation [1-3,10,11]. In recent years, increasing attention has been given to supramolecular structures, the science of noncovalent assembly in biological systems and chemical processes [12]. Hyperbranched polymers such as polyglycerols (HPG), as a result of their inherent dendritic topology, attract considerable interest for a wide range of optical, medical or reagent-immobilization applications [16].

\section{Results and Discussion}

Here, we describe the free-radical polymerization of $\mathrm{N}$-isopropylacrylamide (NIPAM, 1) in the presence of a chain-transfer agent and its end-group functionalization by condensation with an azo dye. We also investigated the host-guest interaction of the azo-dye-labeled end group with randomly methylated $\beta$-cyclodextrin (RAMEB-CD), and with HPG bearing $\beta-C D$ on top. Thus, the focus of the present study was directed towards the preparation and superstructure formation of a thermo- and $\mathrm{pH}$-responsive polymer bearing an azo dye at the end group. In a first step, a chain-transfer polymerization (CTP) of $N$-isopropylacrylamide (1) was carried out in the presence of 3-mercaptopropionic acid (2) and with 4,4'-azobis(4cyanovaleric acid) as initiator, to achieve a high degree of functionalization and yield of carboxy-terminated PNIPAM 3. Then, the free carboxy end group was transferred in to the corresponding acid chloride by treatment with thionyl chloride, yielding polymers with a propionyl chloride end group (Scheme 1).
The final product 6 was obtained by condensation of $\mathbf{4}$ with the amino group of the dye $N, N$-dimethyl-[4-(4'-aminophenylazo)phenyl]amine (5, Supporting Information File 1). The molecular weight $\left(M_{\mathrm{n}} 3.4 \mathrm{kDa}\right)$ and molecular weight distribution (D 1.3) of $\mathbf{6}$ were determined by size-exclusion chromatography (SEC). A $M_{\mathrm{n}}$ value of $\mathbf{5}$ was also calculated by end-group analysis based on ${ }^{1} \mathrm{H}$ NMR measurements, showing similar results (Supporting Information File 1).

The UV-vis absorption spectrum of $\mathbf{6}$ in water showed the characteristic broad band at $\lambda_{\max } 460 \mathrm{~nm}$, which corresponds to the orange color at $\mathrm{pH} 7$ [17]. However, upon decreasing of the $\mathrm{pH}$ from 7 to 2, a large bathochromic (red) shift takes place, due to the protonation of the azo dye of 6 [17]. As illustrated in Figure 1A this red shift corresponds to an increase of the absorption up to $500-550 \mathrm{~nm}$, whereas the band at $420 \mathrm{~nm}$ decreases. Thus, the protonated azonium tautomer is considered to be the predominant form in the red acidic aqueous solution [17-19].

Due to our general interest in the use of CD in polymer chemistry [3], the interaction of polymer 6 with RAMEB-CD was investigated. The proposed formation of the host-guest structure between the azo-dye end group and the RAMEB-CD cavity was proved by use of 2D ROESY NMR spectroscopy (Supporting Information File 1). The correlation signals between the protons of the RAMEB-CD cavity and the aromatic protons of the azo dye were observed. However, the correlation signals between the RAMEB-CD cavity and the methyl protons of the $N, N$-dimethylamine group of the azo dye were not observed. This indicates a complete inclusion of the azo dye<smiles>C=CC(=O)NC(C)C</smiles> 


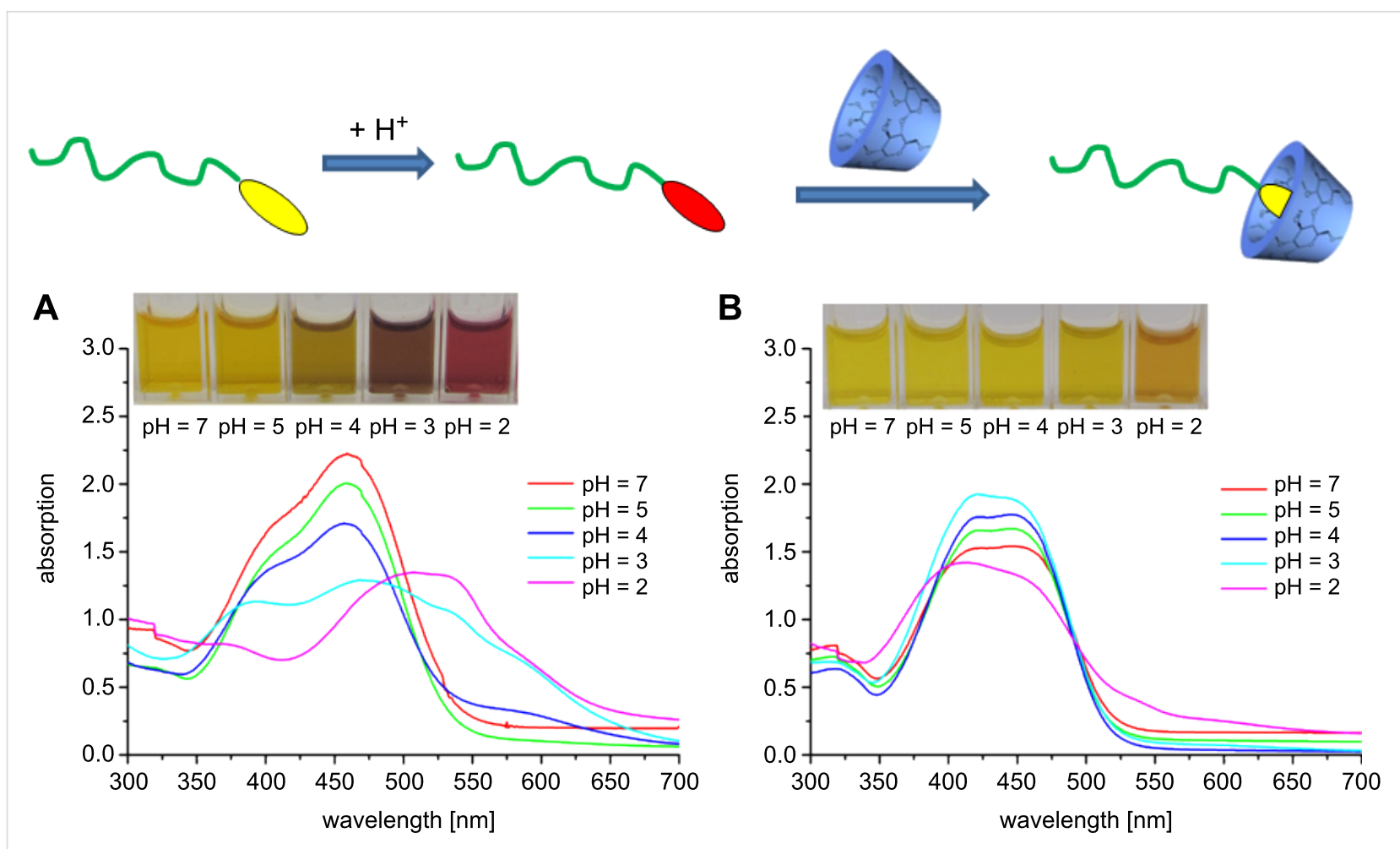

Figure 1: Absorption spectra of 6 in water in a pH range from 7 to 2 (A). Absorption spectra of 6 in water depending on the $\mathrm{pH}$ in the presence of RAMEB-CD (B).

inside the CD cavity with an orientation to the RAMEB-CD axis [1]. In addition, UV-vis absorption spectra of 6 were recorded in aqueous solution at a $\mathrm{pH}$ range from 7 to 2 and in the presence of RAMEB-CD. Hereby, a strong blue shift in the absorption spectra was observed (Figure 1B). As mentioned above, the absorption spectra of $\mathbf{6}$ after protonation indicate the formation of the azonium structure (Figure 1A). The subsequent complexation of this protonated azo dye with RAMEB$\mathrm{CD}$ causes a hypsochromic shift. This strongly indicates that, due to the presence of RAMEB-CD, a shift of the equilibrium from the azonium to the amonium form of the azo dye takes place. Consequently, the azo group in $\mathbf{6}$ is supramolecularly protected from protonation by the surrounding $\mathrm{CD}$ ring, while the free dimethylamino group is easily protonated. These results correspond to the work of Toda et al. [19].

Furthermore, the solution properties of polymer 6, depending on the temperature in the presence of RAMEB-CD, were investigated. As expected, $\mathbf{6}$ is soluble in cold water below the critical solution temperature (LCST). However, due to the hydrophobic azo-dye end group of $\mathbf{6}$, a slight reducing effect on the cloud point in comparison to pure PNIPAM, from 32 down to $29.5^{\circ} \mathrm{C}$ is detected. As a result of complexation of the hydrophobic azodye end group by RAMEB-CD, the cloud point increases from 29.5 back to $32{ }^{\circ} \mathrm{C}$ (Figure 2).
This is strong evidence for the interaction between the hydrophobic azo-dye end group and the hydrophilic RAMEB$\mathrm{CD}$ ring. Based on this experience, the complexation of the azodye end group of 6 with hyperbranched polyglycerol (HPG, 7) decorated with $\beta-C D$ was investigated. This kind of supramolecular structure was generated to illustrate the broad applicability of 6 to generate, e.g., hedgehog-like nanoshapes. Therefore, 7 was prepared according to a procedure described in the literature recently [20-22]. The molecular weight of $7\left(M_{\mathrm{n}}\right.$ $38 \mathrm{kDa}$ ) and the dispersity (D 1.7) were determined by SEC (Supporting Information File 1). To confirm the complexation between the azo-dye-labeled polymers 6 and 7 and the formation of a hedgehog-like superstructure 8, DLS measurements in water were carried out. As expected, the complexation of $\mathbf{6}$ by 7 leads to an increase of the hydrodynamic diameters up to $18 \mathrm{~nm}$ (Figure 3).

The aggregation behavior of complex $\mathbf{8}$ in aqueous solution was also investigated by DLS measurements. Figure 4 shows the temperature dependence of the z-average diameter $\left(D_{\mathrm{Z}}\right)$ of the hedgehog-like nanoshaped polymer 8 . In the temperature range from 25 to $32{ }^{\circ} \mathrm{C}$ no change of $D_{\mathrm{Z}}$ was recorded.

At $33{ }^{\circ} \mathrm{C}$ the $D_{\mathrm{Z}}$ of $\mathbf{8}$ increased up to $21000 \mathrm{~nm}$, but the values showed poor stability because of sedimentation. This means 


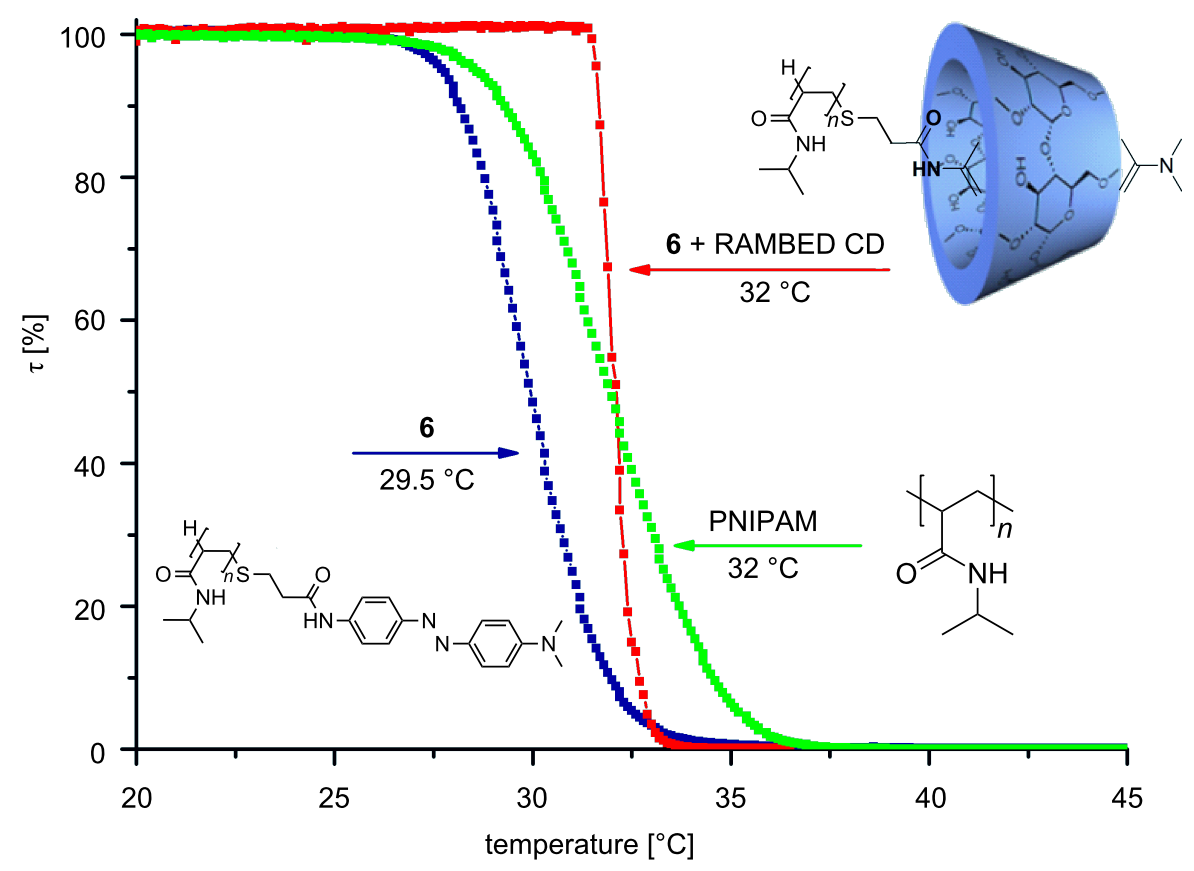

Figure 2: LCST measurements of $\mathbf{6}$, the complex of $\mathbf{6}$ and RAMEB-CD, and in comparison to pure PNIPAM.

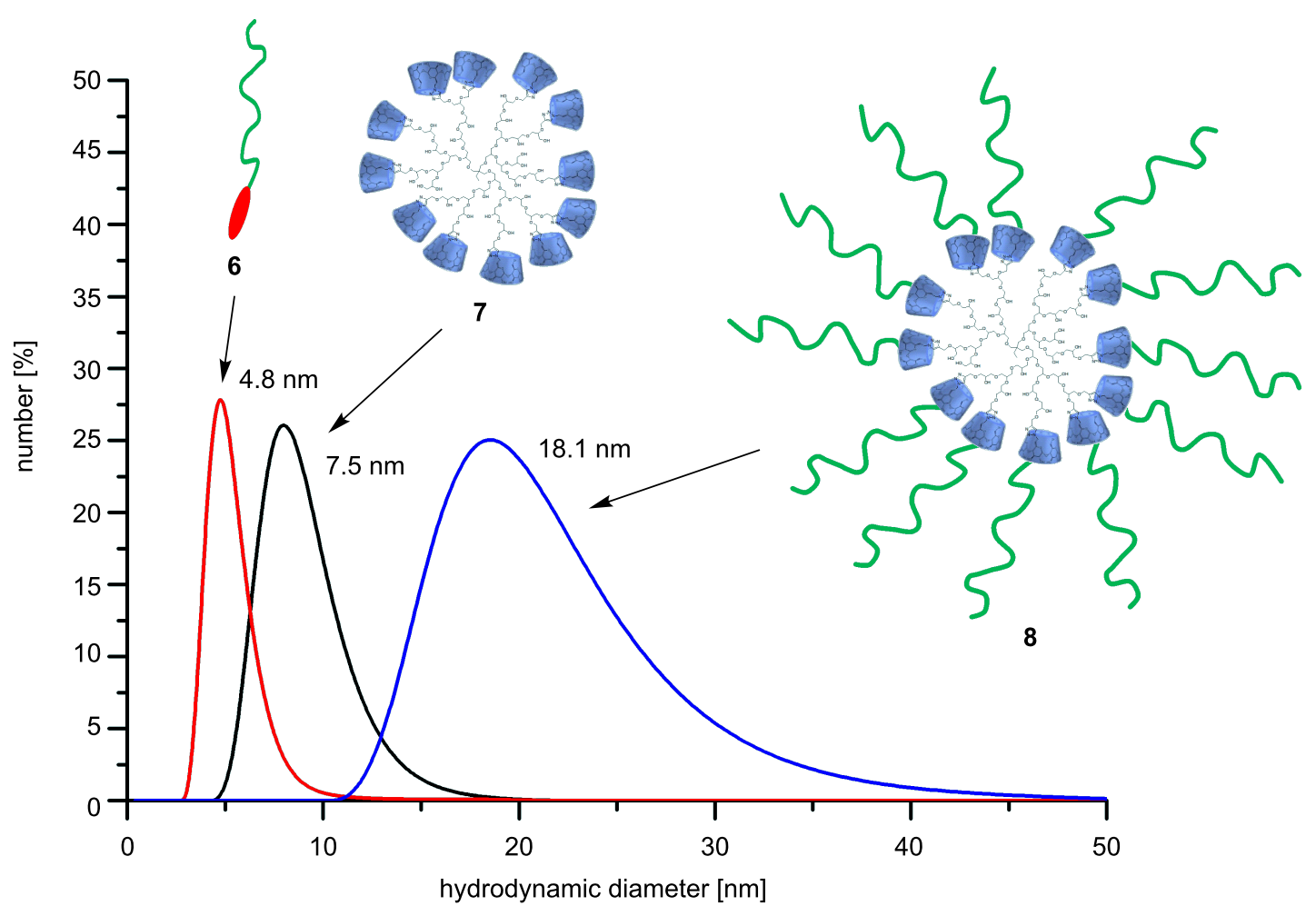

Figure 3: Hydrodynamic diameters of 6,7 and $8(1 \mathrm{mg} / \mathrm{mL})$ at $20^{\circ} \mathrm{C}$. 


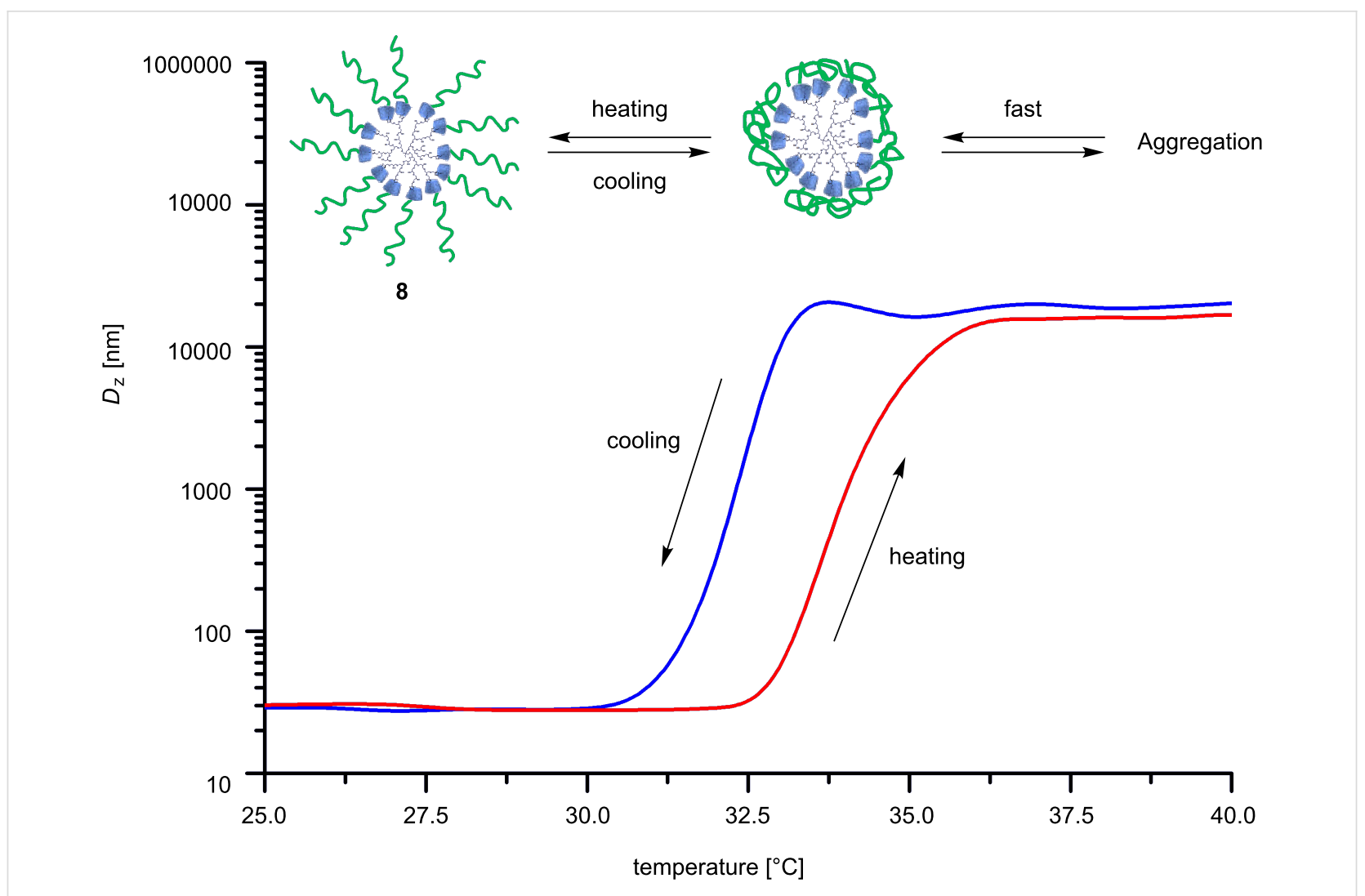

Figure 4: z-Average diameter $\left(D_{Z}\right)$ of the complex 8 in water as a function of temperature $\left(0.5 \mathrm{mg} / \mathrm{mL}\right.$, heating rate $\left.0.5^{\circ} \mathrm{C} / \mathrm{min}\right)$.

that $\mathbf{8}$ is able to form larger particles above the LCST, even resulting in precipitation [23]. However, the change of $D_{Z}$ showed a good reversibility upon cooling. The behavior can be interpreted by the hydrophobic shell of $\mathbf{8}$ and the strong hydrophobic interaction above the LCST, which causes the formation of the large particles.

\section{Conclusion}

In summary, we have presented the synthesis of an azo-dyeend-group-labeled PNIPAM by free-radical polymerization. The acidochromic and thermo-responsive behavior in aqueous solution was analyzed by absorption and cloud-point measurements. In addition, the influences of RAMEB-CD on both effects were investigated. The intermolecular interaction between the dye end group and RAMEB-CD was proven by absorption and 2D ROESY NMR experiments. Furthermore, we were able to show the formation of a hedgehog-like superstructure, based on a hyperbranched polyglycerol, bearing CD moieties, and the end-group-modified PNIPAM 6.

\section{Experimental}

\section{General remarks}

All reagents used were commercially available (Sigma-Aldrich, Acros Organics) and used without further purification.
RAMEB-CD and $\beta-C D$ were obtained from Wacker Chemie $\mathrm{GmbH}$, Burghausen, Germany and were used after being dried overnight with a vacuum oil pump over $\mathrm{P}_{4} \mathrm{O}_{10}$. N,N-Dimethylformamide (DMF) was purchased from Fluka, Germany. Dimethylsulfoxide- $d_{6}(99.9$ atom $\%$ D) and deuterium oxide, $\mathrm{D}_{2} \mathrm{O}$ were obtained from Deutero $\mathrm{GmbH}$, Germany.

${ }^{1} \mathrm{H}$ NMR spectra were recorded on a Bruker Avance DRX 300 at $20{ }^{\circ} \mathrm{C}$ by using DMSO- $d_{6}$ or deuteriumoxide $(99.9 \%)$ as solvents. FTIR spectra were recorded on a Nicolet 6700 FTIR spectrometer equipped with an ATR unit. The absorption spectra were measured in $1 \mathrm{~cm}$ quartz cells on a Specord 210 Plus UV-visible spectrophotometer (Analytik Jena AG, Germany). SEC-MALS measurements were carried out on a combined system comprising the following elements: refractive-index detector Optilabrex (Wyatt Technologies, laser wavelength $658 \mathrm{~nm}$ ), three-angle light-scattering detector miniDawn TREOS (Wyatt Technologies, laser wavelength $658 \mathrm{~nm}$, detector angles at $43.5^{\circ}, 90.0^{\circ}$ and $136.5^{\circ}$ ), UV detector Waters 486 (Waters), column set of HEMAbio 300 and HEMAbio 100 (MZ-Analysentechnik), pump, degasser and autosampler (Agilent 1200, Agilent technologies). The eluent was ultrapure water at a flow rate $1 \mathrm{~mL} / \mathrm{min}$. The molecular weight was calculated with Astra5 software from static-light- 
scattering data, by using the Zimm model. As concentration source, the refractive index was used. Calibration of the system was performed with bovin serum albumin. Turbidity experiments were performed on a Tepper cloud-point photometer TP1. The relative transmission of a laser beam with a wavelength of $670 \mathrm{~nm}$ was recorded for each experiment. The measurements were performed in a temperature range between 5 and $60^{\circ} \mathrm{C}$ and at a heating rate of $1{ }^{\circ} \mathrm{C} \mathrm{min}-1$ by using Hellma Suprasil precision cells 110 Q-S. Critical solution temperatures derived from these experiments were determined at 50\% relative transmission. Dynamic light scattering (DLS) experiments were carried out with a Malvern Zetasizer Nano; ZS ZEN 3600 at a temperature of $20{ }^{\circ} \mathrm{C}$. The particle size distribution is derived from a deconvolution of the measured intensity autocorrelation function of the sample by a general purpose method, i.e., the non-negative least squares algorithm, included in the DTS software.

Synthesis of 3. $N$-Isopropylacrylamide $(1,2 \mathrm{~g}, 0.02 \mathrm{~mol})$ was dissolved in $10 \mathrm{~mL}$ of ethanol and flushed with argon for $15 \mathrm{~min}$. To this solution, 3-mercaptopropionic acid (2, $0.1 \mathrm{~mL}$, $1 \mathrm{mmol}$ ) and 4,4'-azobis(4-cyanovaleric acid) (24.7 mg, $0.09 \mathrm{mmol}$ ) were added under an argon atmosphere. After being stirred at $70{ }^{\circ} \mathrm{C}$ overnight, the corresponding polymer was separated by precipitation with cold diisopropyl ether. The precipitate was washed three times with diethyl ether and dried under reduced pressure. FTIR (diamond) $v\left(\mathrm{~cm}^{-1}\right): 3287(\mathrm{NH}), 2970$ $(\mathrm{CH}), 2930(\mathrm{CH}), 1712(\mathrm{CO}), 1640(\mathrm{CO}), 1539(\mathrm{NH}), 1456$ $(\mathrm{CH}), 1365(\mathrm{CH}), 1230\left(\mathrm{CH}_{2}\right), 1171(\mathrm{CC}) ;{ }^{1} \mathrm{H}$ NMR $(300 \mathrm{MHz}$, $\left.\mathrm{D}_{2} \mathrm{O}\right) \delta 7.19$ (br, 1H, NH), 3.85 (br, 1H, CH), 2,67 (br, 2H, $\mathrm{CH}_{2}$ ), 2,4 (br, 2H, $\mathrm{CH}_{2}$ ), 1.3-2.2 (backbone), $1.02 \mathrm{ppm}$ (s, 6H, $\mathrm{CH}_{3}$ ).

Synthesis of 6. The carboxy-terminated PNIPAM $(3,2 \mathrm{~g})$ was dissolved in $5 \mathrm{~mL}$ of dry DMF. To this solution, thionyl chloride $(0.15 \mathrm{~mL}, 2 \mathrm{mmol})$ and triethylamine $(0.28 \mathrm{~mL}, 2 \mathrm{mmol})$ were added and stirred for $3 \mathrm{~h}$. The precipitated triethylammonium chloride was filtered and the excess of thionyl chloride was removed in vacuum from the DMF-solution. To the obtained solution, triethylamine $(0.28 \mathrm{~mL}, 2 \mathrm{mmol})$ and $N, N$ dimethyl-[4-(4'-aminophenylazo)phenyl]amine (5, $360 \mathrm{mg}$, $1.5 \mathrm{mmol}$ ) were added and stirred overnight at room temperature. The triethylammonium chloride was filtered off, and the terminated polymer was isolated by precipitation with cold diisopropyl ether. The precipitate was washed three times with diethyl ether and dried under reduced pressure. FTIR (diamond) $v\left(\mathrm{~cm}^{-1}\right): 3287(\mathrm{NH}), 2970(\mathrm{CH}), 2930(\mathrm{CH}), 1712(\mathrm{CO}), 1640$ $(\mathrm{CO}), 1539(\mathrm{NH}), 1456(\mathrm{CH}), 1365(\mathrm{CH}), 1230\left(\mathrm{CH}_{2}\right), 1171$ (CC), $881(\mathrm{CN}), 838$ (aromatic $\mathrm{C}-\mathrm{H}, 2$ neighboring $\mathrm{H}$ atoms); ${ }^{1} \mathrm{H}$ NMR (300 MHz, DMSO-d 6 ) $\delta 7.97$ (d, $\left.8.88 \mathrm{~Hz}, \mathrm{ArH}\right), 7.98$ (d, $7.15 \mathrm{~Hz}, \mathrm{ArH}), 7.58$ (d, $7.17 \mathrm{~Hz}, \operatorname{ArH}), 7.36$ (d, $8.88 \mathrm{~Hz}$,
ArH) 7.20 (br, NH), $3.84(\mathrm{~s}, \mathrm{CH}), 2.62\left(\mathrm{br}, \mathrm{CH}_{2}\right), 2.46$ (br, $\mathrm{CH}_{2}$ ), 1.3-2.2 (backbone), $1.04 \mathrm{ppm}\left(\mathrm{s}, 6 \mathrm{H}, \mathrm{CH}_{3}\right.$ ); SEC measurements: $M_{\mathrm{n}} 3.4 \mathrm{kDa}, P_{\mathrm{D}} 1.3 ;{ }^{1} \mathrm{H}$ NMR: $3.3 \mathrm{kDa}$.

\section{Supporting Information}

The Supporting Information contains experimental procedures for the preparation of $\mathbf{5}, \mathrm{HPG}$, propargyl-modified HPG, CD-monoazide, HPG bearing $\beta-C D(7)$, and spectroscopic data of $\mathbf{6}$ and the complex of $\mathbf{6}$ and RAMEB-CD.

\section{Supporting Information File 1}

Experimental procedures and spectroscopic data. [http://www.beilstein-journals.org/bjoc/content/ supplementary/1860-5397-8-224-S1.pdf]

\section{References}

1. Tomatsu, I.; Hashidzume, A.; Harada, A. J. Am. Chem. Soc. 2006, 128, 2226-2227. doi:10.1021/ja058345a

2. Bergbreiter, D. E.; Osburn, P. L.; Li, C. Org. Lett. 2002, 4, 737-740. doi:10.1021/ol017198s

3. Harada, A.; Hashidzume, A.; Yamaguchi, H.; Takashima, Y. Chem. Rev. 2009, 109, 5974-6023. doi:10.1021/cr9000622

4. Pietsch, C.; Schubert, U. S.; Hoogenboom, R. Chem. Commun. 2011, 47, 8750-8765. doi:10.1039/c1cc11940k

5. Koopmans, C.; Ritter, H. J. Am. Chem. Soc. 2007, 129, 3502-3503. doi:10.1021/ja068959v

6. Jochum, F. D.; Theato, P. Chem. Commun. 2010, 46, 6717-6719. doi:10.1039/c0cc01288b

7. Beija, M.; Charreyre, M.-T.; Martinho, J. M. G. Prog. Polym. Sci. 2011, 36, 568-602. doi:10.1016/j.progpolymsci.2010.06.004

8. Bergbreiter, D. E.; Frels, J.; Heuze, K. React. Funct. Polym. 2001, 49, 249-254. doi:10.1016/S1381-5148(01)00087-6

9. Tomatsu, I.; Peng, K.; Kros, A. Adv. Drug Delivery Rev. 2011, 63, 1257-1266. doi:10.1016/j.addr.2011.06.009

10. Kuad, P.; Miyawaki, A.; Takashima, Y.; Yamaguchi, H.; Harada, A. J. Am. Chem. Soc. 2007, 129, 12630-12631. doi:10.1021/ja075139p

11. Goto, H.; Ohta, R. Macromol. Chem. Phys. 2010, 211, 2071-2080. doi:10.1002/macp.201000168

12. Yamaguchi, H.; Kobayashi, Y.; Kobayashi, R.; Takashima, Y.; Hashidzume, A.; Harada, A. Nat. Commun. 2012, 3, No. 603. doi:10.1038/ncomms 1617

13. Bléger, D.; Liebig, T.; Thiermann, R.; Maskos, M.; Rabe, J. P.; Hecht, S. Angew. Chem. 2011, 123, 12767-12771. doi:10.1002/ange.201106879

14. Böhm, I.; Kreth, S. K.; Ritter, H. Beilstein J. Org. Chem. 2011, 7, 1130-1134. doi:10.3762/bjoc.7.130

15. Böhm, I.; Kreth, S. K.; Ritter, H.; Branscheid, R.; Kolb, U.

Macromol. Chem. Phys. 2012, 213, 243-248.

doi:10.1002/macp.201100259

16. Duan, Q.; Miura, Y.; Narumi, A.; Shen, X.; Sato, S.-I.; Satoh, T.; Kakuchi, T. J. Polym. Sci., Part A: Polym. Chem. 2006, 44, 1117-1124. doi:10.1002/pola.21208 
17. Jochum, F. D.; Zur Borg, L.; Roth, P. J.; Theato, P. Macromolecules 2009, 42, 7854-7862. doi:10.1021/ma901295f

18. Sawunyama, P.; Jackson, M.; Bailey, G. W. J. Colloid Interface Sci. 2001, 237, 153-157. doi:10.1006/jcis.2001.7530

19. Kuwabara, T.; Nakamura, A.; Ueno, A.; Toda, F. J. Phys. Chem. 1994, 98, 6297-6303. doi:10.1021/j100076a011

20. Sunder, A.; Mülhaupt, R.; Haag, R.; Frey, H. Macromolecules 2000, 33, 253-254. doi:10.1021/ma9915881

21. Sunder, A.; Hanselmann, R.; Frey, H.; Mülhaupt, R. Macromolecules 1999, 32, 4240-4246. doi:10.1021/ma990090w

22. Sisson, A. L.; Papp, I.; Landfester, K.; Haag, R. Macromolecules 2009, 42, 556-559. doi:10.1021/ma802238e

23. Liu, Y.-Y.; Zhong, Y.-B.; Nan, J.-K.; Tian, W. Macromolecules 2010, 43, 10221-10230. doi:10.1021/ma1019973

\section{License and Terms}

This is an Open Access article under the terms of the Creative Commons Attribution License

(http://creativecommons.org/licenses/by/2.0), which permits unrestricted use, distribution, and reproduction in any medium, provided the original work is properly cited.

The license is subject to the Beilstein Journal of Organic Chemistry terms and conditions:

(http://www.beilstein-journals.org/bjoc)

The definitive version of this article is the electronic one which can be found at: doi:10.3762/bjoc. 8.224 